\title{
Size effects of nanoindentation creep
}

\author{
H. Li and A.H.W. Ngan \\ Department of Mechanical Engineering, The University of Hong Kong, Pokfulam Road, \\ Hong Kong, People's Republic of China
}

(Received 24 July 2003; accepted 15 October 2003)

The size effects on indentation creep were studied on single-crystal $\mathrm{Ni}_{3} \mathrm{Al}$, polycrystalline pure $\mathrm{Al}$, and fused quartz samples at room temperature. The stress exponents were measured by monitoring the displacement during constant indentation loads after correction for thermal drift effects. The stress exponents were found to exhibit a very strong size effect. In the two metals $\mathrm{Al}$ and $\mathrm{Ni}_{3} \mathrm{Al}$, the stress exponent for very small indents is very small, and for Al, this even approaches unity, suggesting that linear diffusional flow may be the controlling mechanism. The stress exponents in these two metals rise rapidly to over 100 as the indent size gets larger, indicating a rapid change of the dominating mechanism to climb-controlled to eventually glide-controlled events. In fused quartz, the stress exponent also exhibits a sharply rising trend as the indent size increases. The stress exponent is also close to unity at the smallest indents studied, and it rises rapidly to a few tens as the indent size gets larger.

\section{INTRODUCTION}

A material surface making a submicrometer-scale plastic contact with a rigid indenter represents an interesting system to investigate. The nominal pressure in this situation is often very high and can easily reach a few percent of the Young's modulus of the material, so that the ideal strength situation is approached. In crystalline metals, the dislocation density in the contact region is also very high, and independent studies ${ }^{1,2}$ have indicated that the dislocation density can exceed $10^{16} \mathrm{~m}^{-2}$. Such contacts are known to creep at an enormous speed at low homologous temperatures at which the same material in the bulk condition would normally not exhibit any creep. ${ }^{3-13}$ As an example, the nanoindentation results by Feng and $\mathrm{Ngan}^{11}$ indicate that in $\mathrm{Ni}_{3} \mathrm{Al}$, an intermetallic compound for high-temperature structural use, the indenter displacement rate $\dot{h}$ after $10 \mathrm{~min}$ of load hold at room temperature becomes steady at approximately 0.01 $\mathrm{nm} / \mathrm{s}$ when the indenter displacement $(h)$ is about 200 $\mathrm{nm}$. The indentation creep rate $\dot{h} / h$ is therefore of the order $5 \times 10^{-5} \mathrm{~s}^{-1}$, which is an enormous creep rate for a high-melting-point material at room temperature. For high-melting materials for which room temperature is normally too low for bulk creep to happen, the occurrence of plasticity is found to be a prerequisite condition for room-temperature indentation creep. ${ }^{10,14}$ For lowmelting metals like indium, which will creep at room temperature anyway even in the bulk condition, the stress exponent is nevertheless found to be different before and after the strain burst, ${ }^{10}$ indicating crystal plasticity will alter the mechanism of indentation creep in these materials.

The mechanism leading to such high values of creep rate in submicrometer indents is so far unknown. $\mathrm{Li}$ et al. ${ }^{15}$ have proposed a number of models for indentation creep in the macroscopic situation, but understanding of the nanoindentation creep is very limited. In particular, it is not known how the behavior and mechanism of the creep change as the indent size gets smaller toward the incipient plasticity situation. Apart from being an interesting problem to investigate, the creep of submicrometer contacts also has important practical implications. In miniaturized mechanical systems, for example, submicrometer contacts are inevitable and their excessive creep may lead to increased friction due to enlargement of the contact area, which is not anticipated in the design stage. In the technique of measuring elastic modulus and hardness by nanoindentation, ${ }^{16}$ it has become well known that indentation creep effects can lead to significant errors in the measurement. ${ }^{11-13}$

The purpose of the current work is to investigate the characteristics of submicrometer indentation creep. While the submicrometer-scale hardness of crystalline materials is well known to exhibit an indentation size effect, ${ }^{17-20}$ the possible appearance of a size effect of indentation creep has never been systematically investigated before, although Elmustafa and Stone have reported a load dependence of the strain-rate sensitivity of hardness in $\mathrm{Al}$ and brass. ${ }^{20}$ In this work, the size effect on the indentation creep in a range of materials at different constant-load conditions is investigated. The materials 
chosen include a single crystal of $\mathrm{Ni}_{3} \mathrm{Al}$, a polycrystalline $\mathrm{Al}$ specimen, and a fused quartz sample. These represent different structures and melting points.

\section{EXPERIMENTAL}

\section{A. Specimen preparation}

The $\mathrm{Ni}_{3} \mathrm{Al}$ single crystal was grown by the Bridgeman method. The composition of this material is Ni-75, Al16.7, Cr-8, and B-0.3 (in at.\%). The crystal was homogenized at $1250{ }^{\circ} \mathrm{C}$ for $120 \mathrm{~h}$ in a vacuum better than $10^{-6}$ torr followed by furnace cooling. A specimen button with (111) direction was cut and electropolished in a solution containing $10 \%$ perchloric acid in ethanol to remove any mechanical deformation layer.

The polycrystalline Al sample ( $>99.99 \%$ pure) was first mechanically polished to $1 \mu \mathrm{m}$ followed by etching in $\mathrm{NaOH}$ solution and electropolishing in an electrolyte containing $10 \%$ perchloric acid in alcohol. Such a process produced a mirror surface with grain size of about $800 \mu \mathrm{m}$. Indentations on the $\mathrm{Al}$ sample were performed within the same grain so that the effects of crystallographic orientation are the same for all the indentation results reported below. The fused quartz is a standard calibration sample supplied by the manufacturer of our Hysitron TriboScope nanoindenter (Hysitron, Minneapolis, MN).

\section{B. Indentation}

Indentation experiments with maximum loads lower than $8 \mathrm{mN}$ were carried out at ambient temperature using both a Hysitron TriboScope and a CSM nanoindentation testing system (CSM Instruments SA, Peseux, Switzerland). For maximum loads higher than the limit of $8 \mathrm{mN}$ of the Hysitron machine, only the CSM machine was used. The Hysitron transducer is mounted on a ThermoMicroscopes Scanning Probe Microscope (ThermoMicroscopes, Sunnyvale, CA). The system can be used as an atomic force microscope using the indentation tip, so that nanoindentation and atomic force microscopy (AFM) imaging can be performed on the same platform. The CSM machine is used due to its larger force and displacement ranges when compared with the Hysitron system. The CSM indenter is also equipped with an atomic force microscope objective for imaging the indent. Although two different indentation machines were used in the current study, the two machines are found to give very consistent results. Repeated testing has shown that the displacement responses from both instruments at the same load are very similar.

All the indentation experiments were performed with Berkovich indenters. Before starting the indentation test, efforts were made to minimize the effects of thermal drift by allowing several hours for thermal equilibrium to be reached. When an indenter is pressed into the surface of a material, it penetrates into the material first because of yielding and then by creeping. Unless stated otherwise, the loading sequences used are similar to the one shown in Fig. 1. The indenter was first loaded and unloaded a few times at constant rates to produce time-independent plastic deformation. The load was then held constant for a period of $100 \mathrm{~s}$ typically at $10 \%$ of the peak to measure the thermal drift rate. For the case that the peak load is over $8 \mathrm{mN}$, this percentage was lower still to avoid creep during the low-load hold. Following the low-load holding period, the specimen was loaded once again to the peak load followed by another holding period of $100 \mathrm{~s}$ at the peak load to monitor the creep response. Finally, another low-load hold follows to determine whether the thermal drift rate has changed significantly during the course of the experiment; data where the drift rate has changed significantly were discarded. The loading and unloading time was $3 \mathrm{~s}$ in all the experiments to ensure the same number of data points acquired. Before testing, both the tip shape and the machine compliance were calibrated using a standard sample of fused quartz. Indentation at each load value was repeated five or more times. Each indent was imaged before indentation afterwards using AFM to ensure similar surface conditions for all the indentations.

In the current work, one major concern is the stability of the indentation equipment, and care has been exercised as mentioned above to minimize and to handle the thermal drift. One critical test to show the equipment stability is to make sure that no creep is recorded in a situation where no creep is supposed to take place. It is well known ${ }^{10,14}$ that in well-annealed, higher-melting metals, no creep will take place at a load smaller than that required to trigger indentation plasticity, and hence this condition can be used to check equipment stability. Figure 2 in fact shows that no creep is recorded in our equipment in such conditions in our $\mathrm{Ni}_{3} \mathrm{Al}$ sample, and hence the required system stability can be ascertained. More about this will be discussed in Sec. III. A.

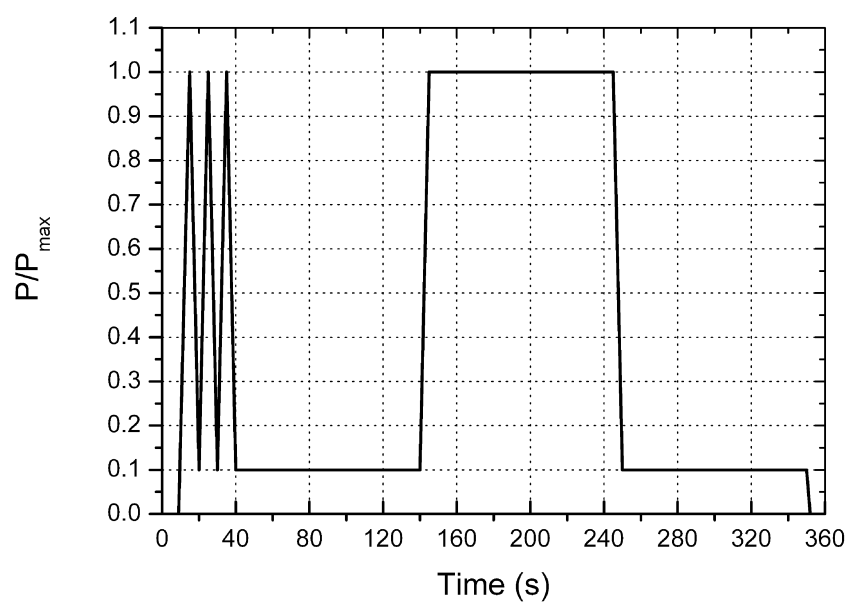

FIG. 1. Constant-load scheme. 


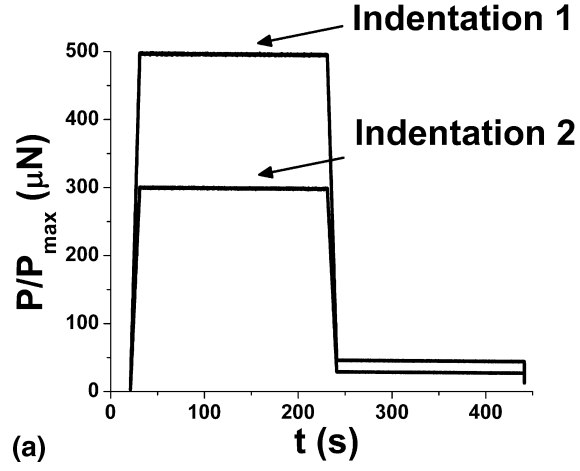

(a)

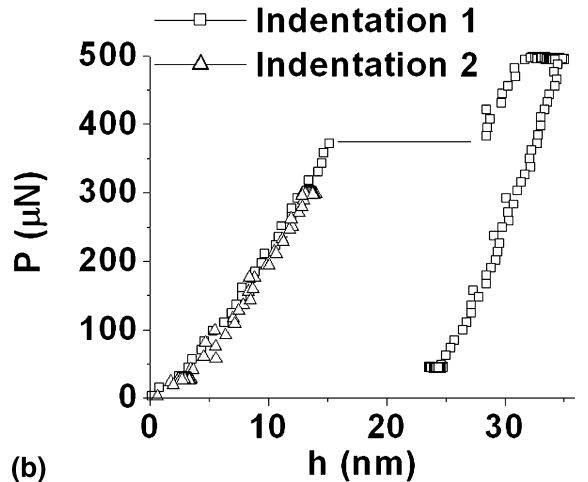

(b)

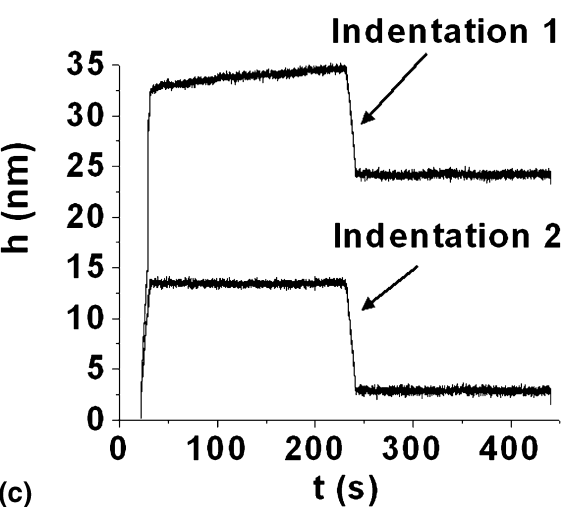

(c)

$t(s)$

FIG. 2. An experiment to illustrate the absence of creep before pop-in in the same $\mathrm{Ni}_{3} \mathrm{Al}$ sample used in the current work (data extracted from Ref. 28). (a) Load schedules at two different peak loads below and above the pop-in load. (b) Load-displacement curves for the two load schedules. (c) Displacement versus time curves for the two load schedules. During load hold below the pop-in load, the deformation is purely elastic and there is no creep. Creep occurs during load hold above the pop-in load.

\section{Data treatment}

In uniaxial tests, it is well known that the steady-state creep behavior of a wide range of materials can be described by the relation, ${ }^{21}$

$$
\dot{\epsilon}=A \sigma^{n},
$$

where $\dot{\epsilon}$ is the strain rate, $\sigma$ the applied stress, and $n$ the stress exponent. The pre-factor $A$ contains the temperature dependence through the Boltzmann factor. The stress exponent $n$, which is given by the slope of the $\log -\log$ plot of $\dot{\epsilon}$ versus $\sigma$ under isothermal conditions, can provide useful information on the mechanism of the time-dependent plastic deformation concerned.

In depth-sensing indentation with a self-similar indenter, the strain-rate $\dot{\epsilon}$ and the stress $\sigma$ (or hardness) obey the following scaling relations

$$
\dot{\epsilon} \sim \dot{h} / h, \quad \sigma \sim P / h^{2} .
$$

Here $P$ is the indentation load, $h$ is the instantaneous indenter displacement, and $\dot{h}=d h / d t$, where $t$ is time. The scaling relations in Eq. (2) are direct consequences of an exact geometrical similitude analysis of power-law indentation creep by Bower et al. ${ }^{22}$ These authors showed that, in a power-law creeping solid upon indentation by an axisymmetric punch, the stress and strainrate fields scale with the quantities $P / a^{2}$ and $\dot{h}$, respectively, where $a$ is the radius of the contact zone, and in the special case of indentation by a conical punch, the ratio $h / a$ depends only on the stress exponent $n$ [Eqs. (1.8), (1.9), and (1.13) of Ref. 22]. The constant-load experiments in this work here can be supposed to be a purely creeping rather than a viscoelastic situation, and so the results of Bower et al. should apply. Even when elasticity is present alongside viscosity, an exact linear viscoelastic treatment (i.e., $n=1$ ) in fact shows that $P / h^{2} \propto \dot{h} / \mathrm{h}$ during constant load, ${ }^{1,23,24}$ and hence Eq. (2) also applies. Several methods have indeed been used in the literature for the analysis of indentation creep data using Eq. (2). These include (i) the depth-sensing, constant-load ( $h$-CL) method; ${ }^{5-8}$ (ii) the continuousstiffness, constant-load (S-CL) method; ${ }^{25}$ and (iii) the exponential load (EL) method. ${ }^{9}$ The two constant-load methods use data from a load hold at the maximum load. The $h$-CL method makes use of the depth data (hence " $h$ ") during the load hold, whereas the S-CL method makes use of the contact stiffness data (hence " $S$ ") during the load hold, and the purely elastic result is that $S$ is proportional to $h$ for a conical indenter. ${ }^{26}$ In the EL method due to Lucas and Oliver, ${ }^{9}$ the load is increased exponentially with time, or $\dot{P} / P$ is kept constant $(=k$, say). These authors argued that if this loading condition is used and if steady state is reached, the measured hardness should reach a constant, and this constant may be taken as the mean stress. The imposed constant ramp rate $k$ can be viewed as the strain rate because it has the correct dimension.

In our experiments here, the $h$-CL method is used to calculate the stress exponent. Because our aim is to study the effect of load on the stress exponent, the EL method is unsuitable as the load involved is continuously increasing. On our machines, the $h$-CL method is simpler to implement than the $S$-CL method, and for the small creep displacements involved during constant load, the contact 
stiffness changes are not easily deconvoluted from the noise background. In the $h$-CL method, the displacement is monitored as a function of time during the load hold. Because the contact area will increase during the holding period if creep occurs, the hardness will consequently decrease with a corresponding decrease in the indentation strain rate. Tabulation of a series of pairs of the strain rate and stress thus enables the calculation of the stress exponent.

To calculate the displacement rate $\dot{h}$, the indenter displacement versus time curve at constant indentation load was fitted by the following empirical law:

$$
h(t)=h_{i}+\beta\left(t-t_{i}\right)^{m}+k t,
$$

where $h_{i}, \beta, t_{i}, m$, and $k$ are fitting constants. The fitting protocol in Eq. (3) is found to produce very good fits to most of our results, as can be seen from the examples shown in Figs. 6-11.

For the scaling of the strain rate and stress according to Eq. (2) to be correct, the indenter tip has to be selfsimilar. On the other hand, the tip head in practice must be rounded with a radius of curvature $R$. Figure 3 shows the AFM scan of the profile of the Berkovich indenter used in our Hysitron system, from which the tip is clearly seen to be rounded. The radius of curvature $R$ of this tip had been determined in a previous exercise ${ }^{2}$ by fitting the load-displacement curve before plasticity on a known sample to a curve predicted by the Hertzian elasticity theory, and $R$ was found this way to be approximately $500 \mathrm{~nm}$. In Fig. 3 is also shown a circle with radius 500 $\mathrm{nm}$ that can be seen to fit accurately to the AFM profile of the indenter near the tip position, and thus the estimated value of the tip radius is confirmed. In an indent made by the indenter, the maximum contact depth below which the indent shape is spherical instead of pyramidal can be estimated by the equation $R\left(1-\sin 70.3^{\circ}=\right.$ $0.06 R$, which gives approximately $30 \mathrm{~nm}$ for an $R$ value of $500 \mathrm{~nm}$. This equation is based on the assumption that the sloping, flat surfaces of the pyramidal indenter make tangential contact with the sphere fitted to the rounded

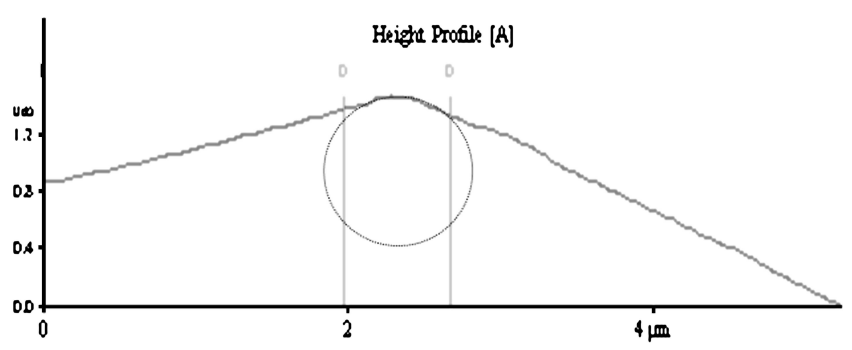

FIG. 3. AFM scan of the profile of the Berkovich indenter used in this work in the Hysitron indenter. The left sloping line of the height profile is the scan along one edge of the three-sided pyramid of the Berkovich inderter, and the right sloping line is along the median line bisecting the opposite flat plane in the pyramid. The dotted circle fitted to the tip of the indenter has a radius of $500 \mathrm{~nm}$. indenter tip, and $70.3^{\circ}$ here is the semi-angle of a Berkovich indenter. Such an estimate for the maximum depth for spherical contact can be seen to agree well with the AFM profile of the tip in Fig. 3-the AFM profile indeed shows that for depths larger than approximately $30 \mathrm{~nm}$, the indent geometry should follow the sloping sides of the indenter rather than the rounded shape of the tip. The maximum indent depth for spherical contact in our CSM indenter was likewise determined to be about $20 \mathrm{~nm} .{ }^{13}$ The smallest indents in $\mathrm{Al}$ (i.e., those immediately after pop-in) have plastic depths larger than $100 \mathrm{~nm}$ and so all the $\mathrm{Al}$ indents are pyramidal and may be regarded as self-similar. In $\mathrm{Ni}_{3} \mathrm{Al}$ and fused quartz, indents shallower than the minimum depth for self-similarity can be generated by very small loads, but when these were encountered, they were excluded in the analysis.

\section{RESULTS}

\section{A. Elastic deformation, pop-in, and creep}

In the metals $\mathrm{Ni}_{3} \mathrm{Al}$ and $\mathrm{Al}$, pop-in occurs at a critical load during a load ramp. If the peak load is below the critical pop-in load, the deformation is purely elastic, except for very long holding times at loads slightly lower than the pop-in load where a delayed type of pop-in may occur. ${ }^{27}$ Holding the load before the occurrence of pop-in does not result in creep. However, holding a load above the pop-in value will produce creep. Figure 2 shows evidence for this in $\mathrm{Ni}_{3} \mathrm{Al},{ }^{28}$ and similar evidence in $\mathrm{Al}$ has already been published elsewhere. ${ }^{10}$

In the amorphous fused quartz, a distinctive pop-in is not observed on increasing load, but when the load is small, the deformation is also elastic whereas for large loads, there is a residual deformation upon load removal. Holding a small load also does not produce creep, but holding a large load above the plasticity threshold will produce creep. This is illustrated in Fig. 4.

\section{B. Size effects of indentation creep}

Figures 5(a)-5(c) shows the creep curves of the three materials during different holding loads. At each load, more than five independent indentations were performed, and the data were averaged to minimize the influence of noises after discarding results differing significantly from the others. To facilitate comparison, the starting points for different peak loads are aligned. It is evident that the creep displacement is larger at higher peak loads. It is also found that the displacement increases at a declining rate with time and finally reaches an almost constant displacement rate, resulting in a decreasing strain rate against time and displacement. It can also be seen by comparing Figs. 5(a)-5(c) that at comparable loads, the indentation creep is fastest in $\mathrm{Al}$ and slowest in fused quartz.

Figure 6(a) shows the experimental displacement-time curve in $\mathrm{Ni}_{3} \mathrm{Al}(111)$ during load hold at $1 \mathrm{mN}$ together 

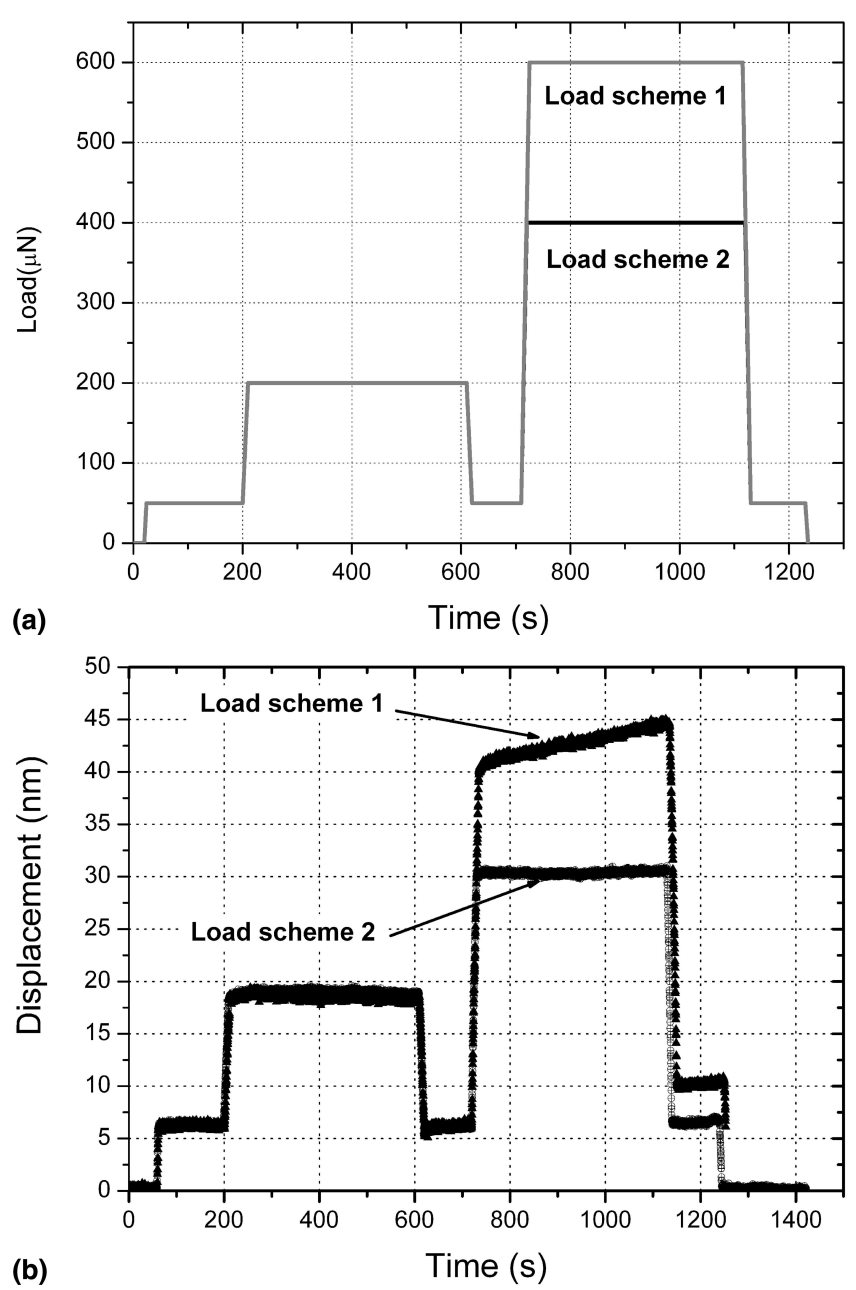

FIG. 4. (a) Two loading schedules to investigate onset of creep plasticity in fused quartz. (b) Indenter displacement versus time plots. Under load scheme 2 in which the holding loads are small, the deformation is elastic throughout. Under load scheme 1, creep occurs during the second holding stage in which the load is larger.

with the fitted curve using Eq. (3). It can be seen that the quality of fit is very good (correlation coefficient $R^{2}>$ 0.97). Figure 6(b) shows the corresponding $\log ($ strain rate) versus $\log$ (stress) plot using the definitions of strain rate and stress according to Eq. (2). It can be seen that the slope of the curve is almost constant with a value of about 3.4. The load of $1 \mathrm{mN}$ here is slightly above the load range where pop-in occurs in $\mathrm{Ni}_{3} \mathrm{Al}$, which is about $0.4 \mathrm{mN}$ (Fig. 2), and smaller indents were not analyzed as in Fig. 6 because these are too shallow to satisfy the self-similarity condition. Figure 7 shows the stress exponent analysis in $\mathrm{Ni}_{3} \mathrm{Al}$ at a larger peak load of $8.5 \mathrm{mN}$ from which it can be seen that the stress exponent at the start of the load hold is very large at 39 , but it decreases toward a steady-state value of about 7 . Comparison of the results in Figs. 6 and 7 indicate that the stress exponent in $\mathrm{Ni}_{3} \mathrm{Al}$ exhibits a very strong dependence on the indent size. The size effect is even more remarkable in Al.
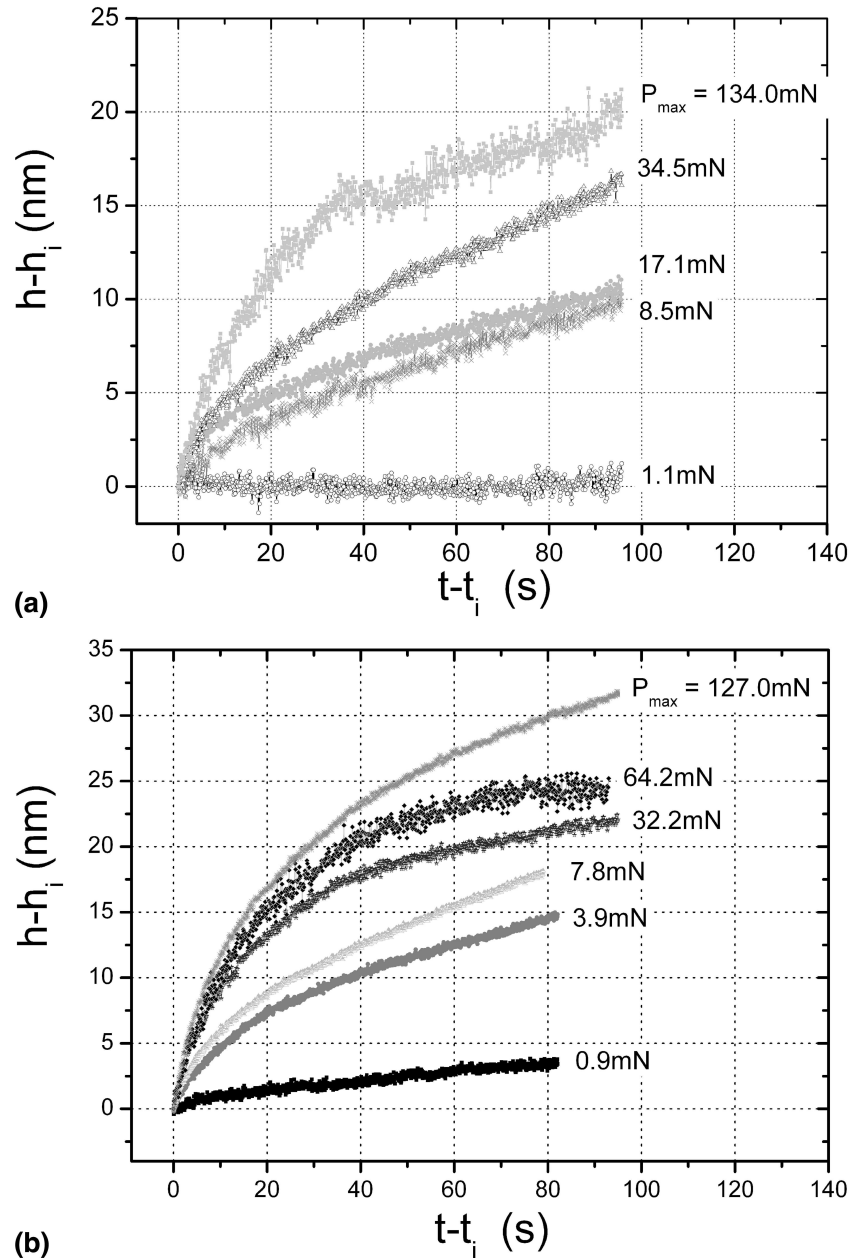

(b)

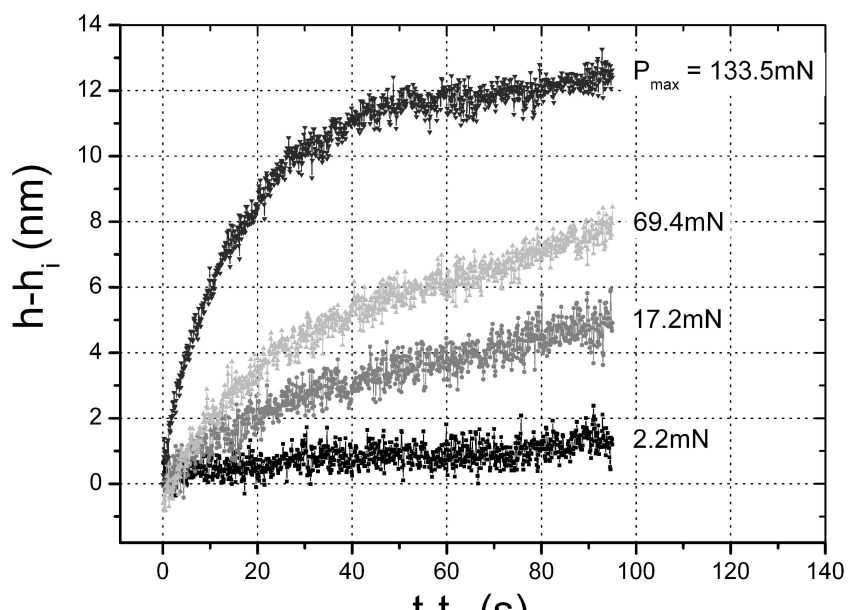

(c)

$t-t_{i}(s)$

FIG. 5. Creep displacement during load hold in the three materials: (a) $\mathrm{Ni}_{3} \mathrm{Al}$ from $1 \mathrm{mN}$ to $134 \mathrm{mN}$, (b) $\mathrm{Al}$ from $1 \mathrm{mN}$ to $127 \mathrm{mN}$, and (c) fused quartz from $2 \mathrm{mN}$ to $134 \mathrm{mN}$. The starting points were aligned to facilitate comparison.

Figures 8 and 9 show the stress exponent analysis in $\mathrm{Al}$ at peak load values of $1 \mathrm{mN}$ and $4 \mathrm{mN}$, respectively. It can be seen that the steady-state stress exponent is about 1 at $1 \mathrm{mN}$, but it increases rapidly to beyond 10 at $4 \mathrm{mN}$. 

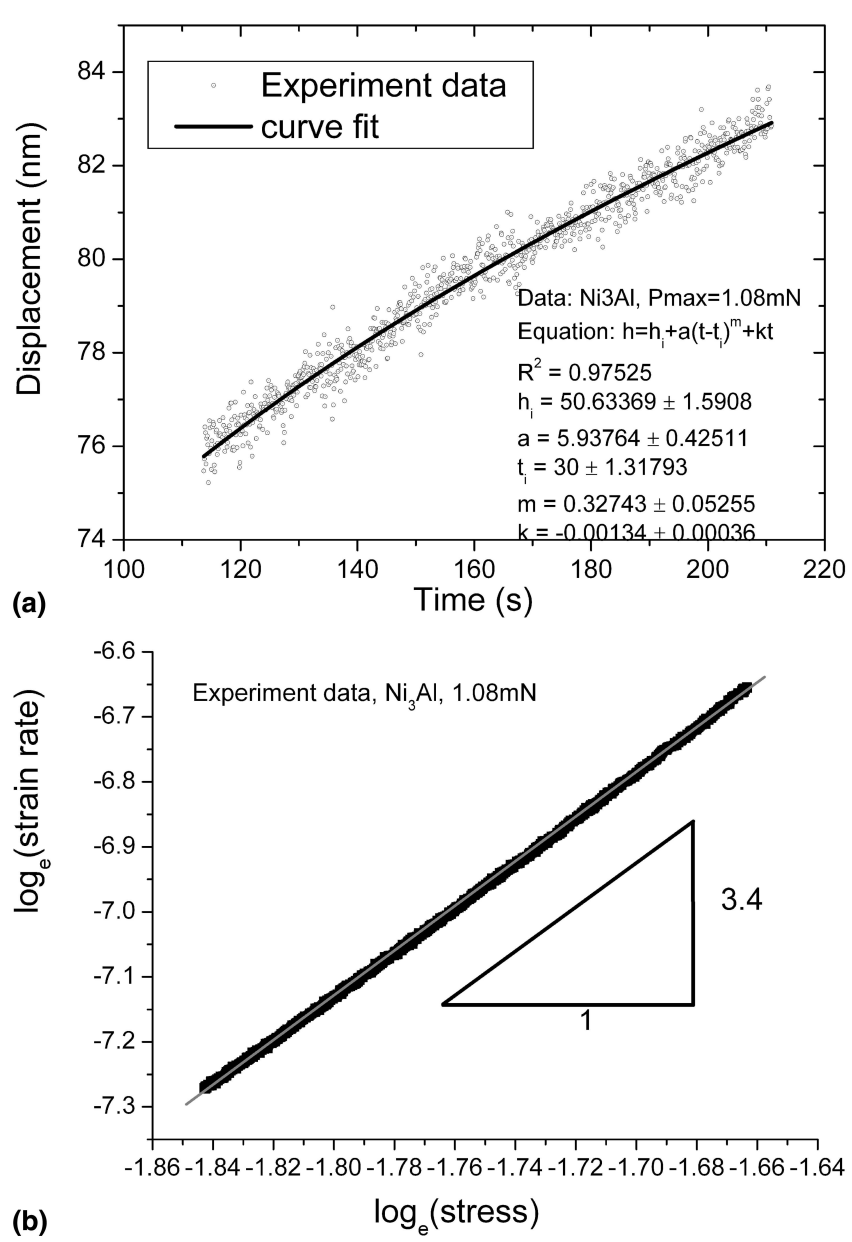

FIG. 6. (a) Experimental and fitted creep curves in $\mathrm{Ni}_{3} \mathrm{Al}(111)$ at $1 \mathrm{mN}$. (b) The corresponding $\log$ (strain rate) $-\log$ (stress) plot (CSM equipment).

The stress exponent in the amorphous fused quartz is also found to exhibit a strong size effect. Figures 10 and 11 show the stress exponent analysis in the fused quartz sample at loads $0.6 \mathrm{mN}$ and $34.3 \mathrm{mN}$. The steady-state stress exponent also rises rapidly from approximately 1 to approximately 39 between these two loads. Figure 12 shows the full set of the steady-state stress exponent data of the three materials plotted as a function of the peak load. The indenter displacement at the start of the load hold is also listed in Fig. 12. It can be seen again that the stress exponent in all the three materials exhibits a strong dependence on indent size. Figure 13 shows the variation between the hardness calculated using the Oliver-Pharr method with the peak load. It can be seen that the hardness in general exhibits a falling trend as the indentation load increases, but such variations are not large.

\section{DISCUSSION}

In the two metals of $\mathrm{Ni}_{3} \mathrm{Al}$ and $\mathrm{Al}$, the previous ${ }^{10,28}$ and current results indicate that plasticity is a prerequisite

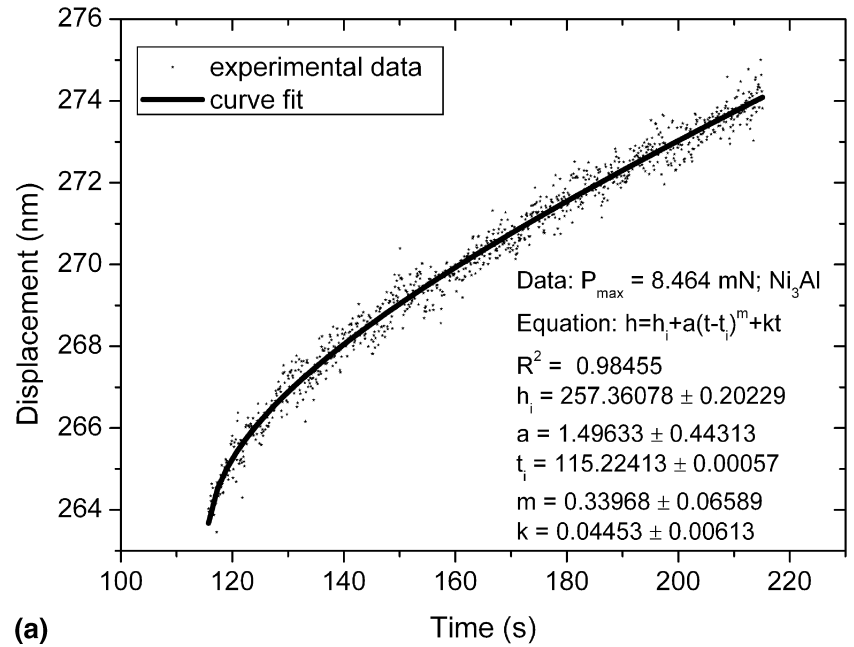

(a)

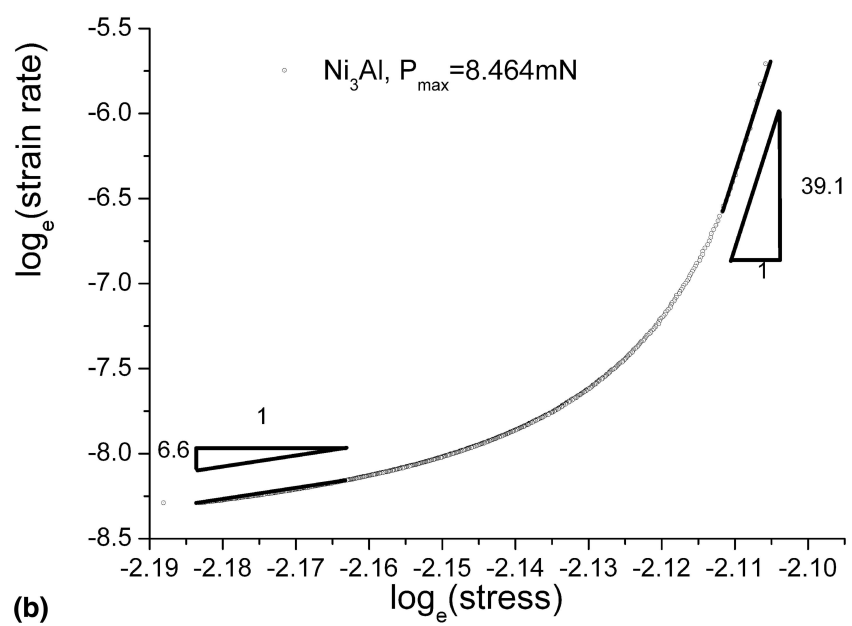

FIG. 7. (a) Experimental and fitted creep curves in $\mathrm{Ni}_{3} \mathrm{Al}(111)$ at load $8.5 \mathrm{mN}$. (b) The corresponding $\log$ (strain rate) $-\log$ (stress) plot (CSM equipment).

for indentation creep during load hold. In other words, the indentation creep in metals are plasticity-induced, and is therefore different from the type of indentation creep in low-melting metals such as indium in which creep can occur even before pop-in. ${ }^{10}$ Diffusion along the interface between the indenter and the specimen surface was once thought to be a possible mechanism leading to indentation creep, ${ }^{29}$ but such a mechanism does not depend on preceding plasticity and is clearly not responsible for the current type of plasticity-induced creep here.

A satisfactory explanation of the plasticity-induced type of indentation creep should obviously relate to the defect debris generated during the plastic deformation. In $\mathrm{Ni}_{3} \mathrm{Al}$, the stress exponent within the range of 3 to 5 in small indents as shown in Fig. 12 is the expected value for the mechanism of dislocation climb via bulk and pipeline diffusion. ${ }^{15,21,30}$ In $\mathrm{Al}$, the observation that the stress exponent is close to unity in the smallest indents suggests that the mechanism is likely to be diffusional 

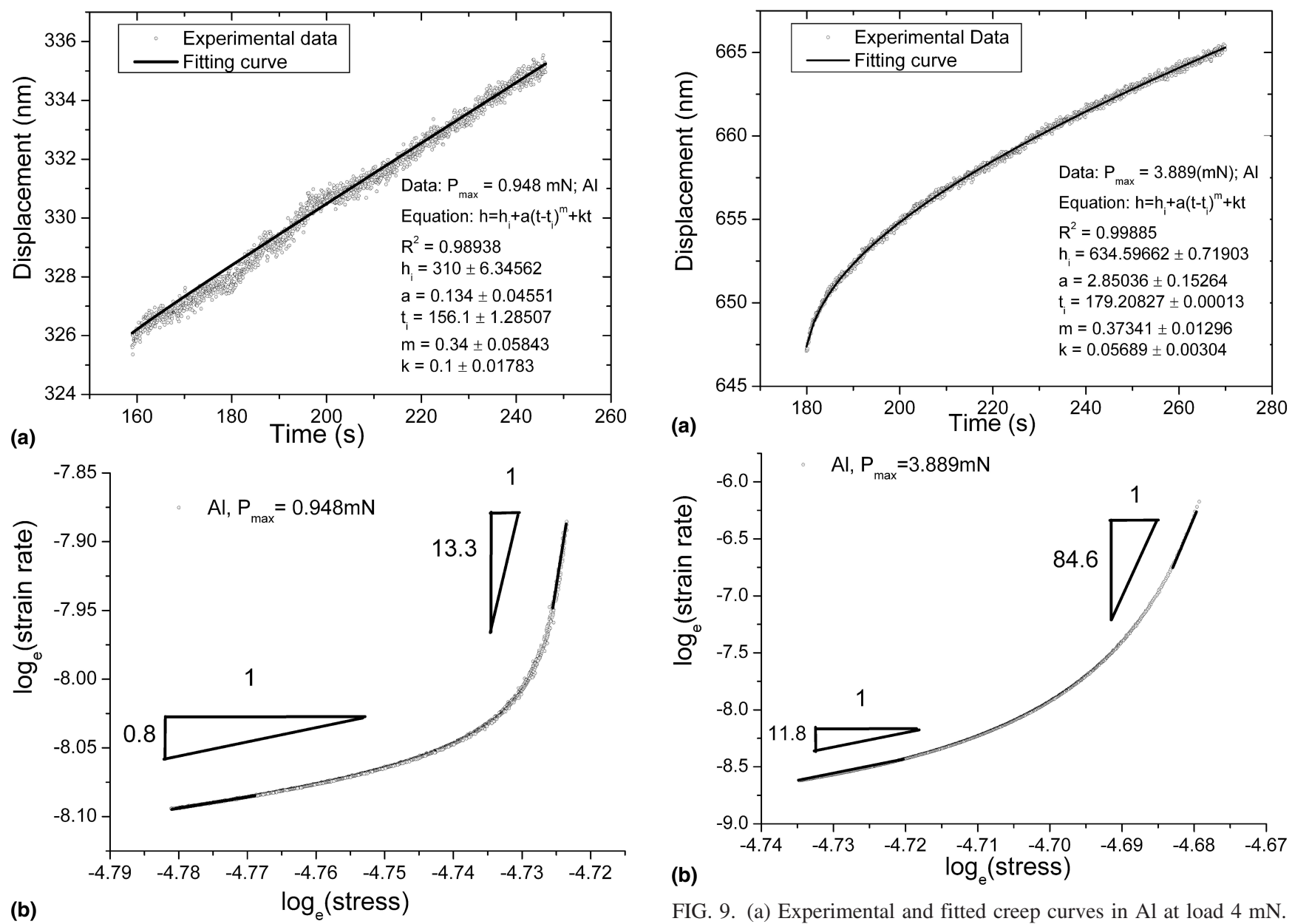

FIG. 8. (a) Experimental and fitted creep curves in $\mathrm{Al}$ at $1 \mathrm{mN}$. (b) The corresponding $\log$ (strain rate)- $\log$ (stress) plot (Hysitron equipment).

flow. This is very unusual because diffusional flow normally occurs at homologous temperatures above 0.5 , but room temperature is only about 0.32 of the melting point of Al. The densely dislocated structure under the indenter may cause diffusional flow to occur more easily in $\mathrm{Al}$, as the dense dislocation channels may act as efficient shortcircuiting diffusion paths for the transport of atoms from the highly stressed indent core to the stress-free specimen surface nearby. This can be understood by a simple diffusional flow model in which the dense dislocation pipelines in the indent core transport atoms from the indent core to low-stress locations such as the nearby free surface just outside the contact zone. Assuming the contact zone radius $a$ to be a typical diffusion length, the representative concentration gradient for the diffusion process is

$$
\frac{\mathrm{d} c}{\mathrm{~d} x} \sim \frac{c_{\mathrm{o}} \sigma \Omega}{a k T},
$$

where $c_{\mathrm{o}}$ is the equilibrium vacancy concentration in the stress-free state, $\sigma$ is the mean stress in the indent core, $\Omega$ is the atomic volume, $k$ is the Boltzmann constant, and

FIG. 9. (a) Experimental and fitted creep curves in $\mathrm{Al}$ at load $4 \mathrm{mN}$. (b) The corresponding $\log$ (strain rate)- $\log$ (stress) plot (Hysitron equipment).

$T$ is the temperature. From Fick's first law, the diffusion flux is therefore

$$
J=\frac{D_{v} \sigma}{a k T}
$$

where $D_{v}$ is the self-diffusion coefficient along pipelines. Assuming the diffusion area to scale with $\pi a^{2}$, say, $\alpha \pi a^{2}$ where $\alpha$ is a geometric factor ( $=2$ if diffusion is radial outward from the indent center), the volume transport rate is

$$
\dot{V}=\alpha \pi a^{2} J \Omega=\frac{\alpha \pi a D_{v} \sigma \Omega}{k T} .
$$

Because $\dot{V} / V=3 \dot{a} / a$, and the volume $V$ of the indent core is $2 \pi a^{3} / 3$, the indentation strain rate is

$$
\dot{\epsilon}=\frac{\dot{a}}{a}=\left(\frac{\alpha}{2}\right) \frac{D_{v} \Omega}{k T a^{2}} \sigma .
$$

The model here therefore predicts a linear relation between strain rate and stress. Because the pre-factor is inversely proportional to the square of the indent size, the mechanism can be expected to be efficient only when the indent size is very small (i.e., when the diffusion length 

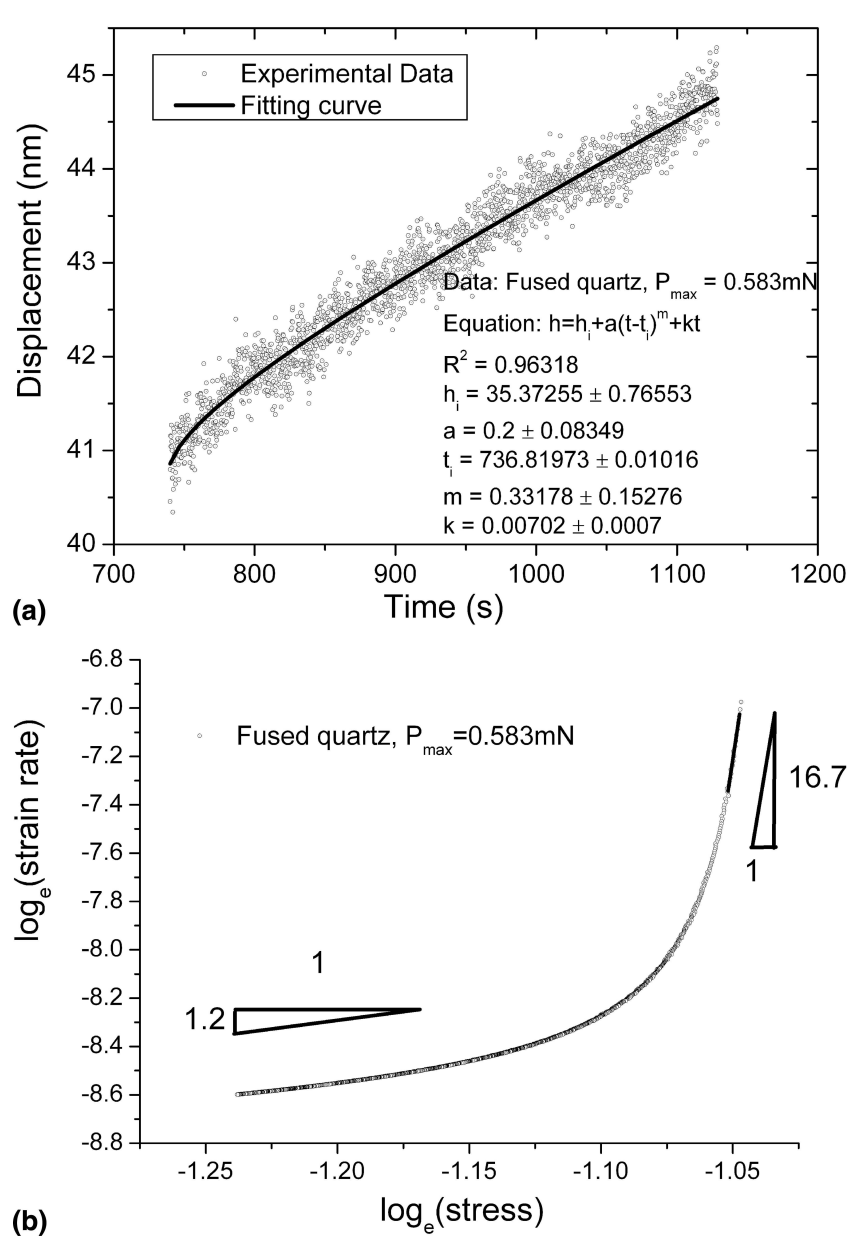

FIG. 10. (a) Experimental and fitted creep curves in fused quartz at $0.6 \mathrm{mN}$. (b) The corresponding $\log$ (strain rate) $-\log$ (stress) plot (Hysitron equipment).

is short). In $\mathrm{Al}$, diffusivity data at room temperature are not available but can nevertheless be estimated if the activation energy is known. The activation energy for pipeline diffusion in $\mathrm{Al}$ has been measured to be about $0.85 \mathrm{eV}{ }^{31}$ Assuming a preexponential factor of $0.02 \mathrm{~cm}^{2} / \mathrm{s}$ and that the lattice is saturated with dislocations, the $D_{v}$ estimated for $\mathrm{Al}$ is approximately $3 \times 10^{-21} \mathrm{~m}^{2} / \mathrm{s}$ at room temperature. For the smallest indents in $\mathrm{Al}$, the diffusion length can be assumed to be approsimately $100 \mathrm{~nm}$, and the hardness about1 GPa. The strain rate estimated from Eq. (7) is of the order $2 \times 10^{-6}$. The experimentally observed strain rate of the smallest indents in $\mathrm{Al}$ is two orders of magnitude higher at about $2 \times 10^{-4} \mathrm{~s}^{-1}$ [Fig. 8(b)]. However, it must be remembered that, in view of the scarcity of the available data, the activation energy assumed here is quite uncertain. If, for example, a value of $0.75 \mathrm{eV}$ instead of the $0.85 \mathrm{eV}$ is assumed, the estimated strain rate would have been approximately $1 \times 10^{-4} \mathrm{~s}^{-1}$, which is the magnitude observed. It can therefore be concluded that the model in Eq. (7) is a reasonable model to explain the observed

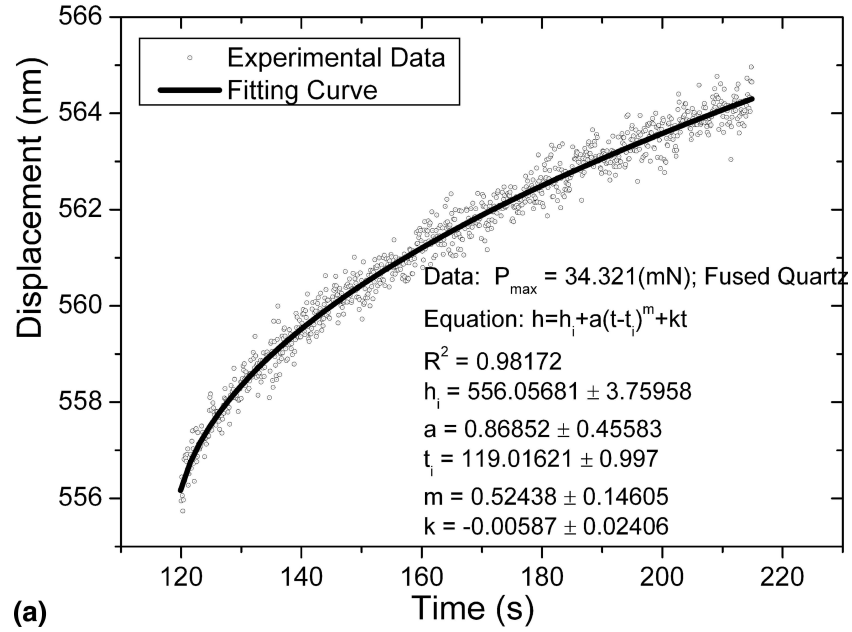

(a)

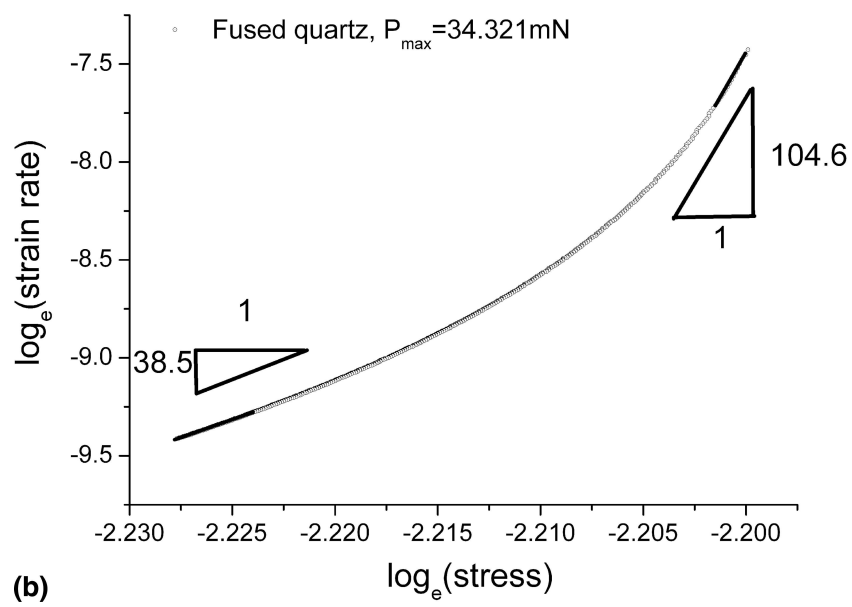

FIG. 11. (a) Experimental and fitted creep curves in fused quartz at load $34.3 \mathrm{mN}$. (b) The corresponding $\log$ (strain rate)- $\log$ (stress) plot (CSM equipment).

linear creep in the smallest indents in Al. A more definitive check would have been to investigate the dependence of the pre-factor on the indent size, to see whether it obeys the inverse-square relationship as in Eq. (7). However, as the indent size increases, the observed stress exponent increases as noted above, and so the creep mechanism cannot be maintained constant.

Under larger loads, the stress exponent of $\mathrm{Ni}_{3} \mathrm{Al}$ and $\mathrm{Al}$ increases rapidly beyond 100, as Fig. 12 shows. This suggests a rapid change of mechanism from linear diffusional flow to a power-law mechanism, such as climb, to eventually a rate-insensitive plastic flow behavior as the indent size gets larger. It should be noted that although superdislocation locks (the Kear-Wilsdorf locks) play an important role in the crystal plasticity of $\mathrm{Ni}_{3} \mathrm{Al}$, the flow stress in the bulk condition is controlled by an athermal unlocking process so that the strain-rate sensitivity, the reciprocal of the stress exponent, is nearly zero. ${ }^{32}$ The matching to macroscopic flow behavior for large indents is not surprising, as one would expect micro- or macroindentation to creep-like bulk deformation. ${ }^{15}$ 


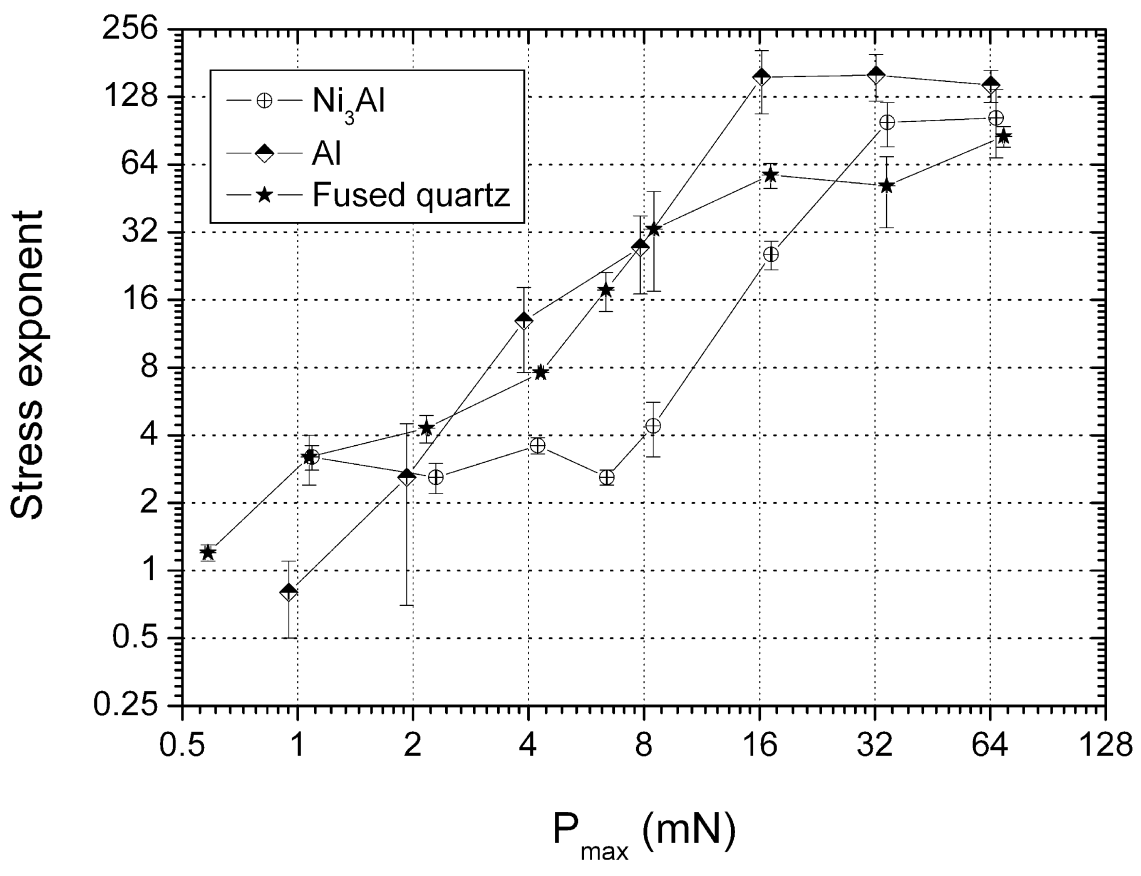

\begin{tabular}{cccccccrrr}
\hline \multicolumn{2}{c}{$\begin{array}{c}\text { Nominal } P_{\text {max }} \\
(\mathrm{mN})\end{array}$} & & 1 & 2 & 4 & 8 & 16 & 32 & 64 \\
\hline Initial indent & $\mathrm{Ni}_{3} \mathrm{Al}$ & 76.0 & 119.0 & 172.9 & 263.4 & 400.6 & 591.4 & 883.8 & 1298.3 \\
depth $(\mathrm{nm})$ & $\mathrm{Al}$ & 308.3 & 452.3 & 647.4 & 948.1 & 1476.7 & 2124.3 & 3137 & 4470.7 \\
& Fused quartz & 65.7 & 105.2 & 164.3 & 262.2 & 384.1 & 556.0 & 807.7 & 1130.0 \\
\hline
\end{tabular}

FIG. 12. Stress exponent versus holding load in three materials.

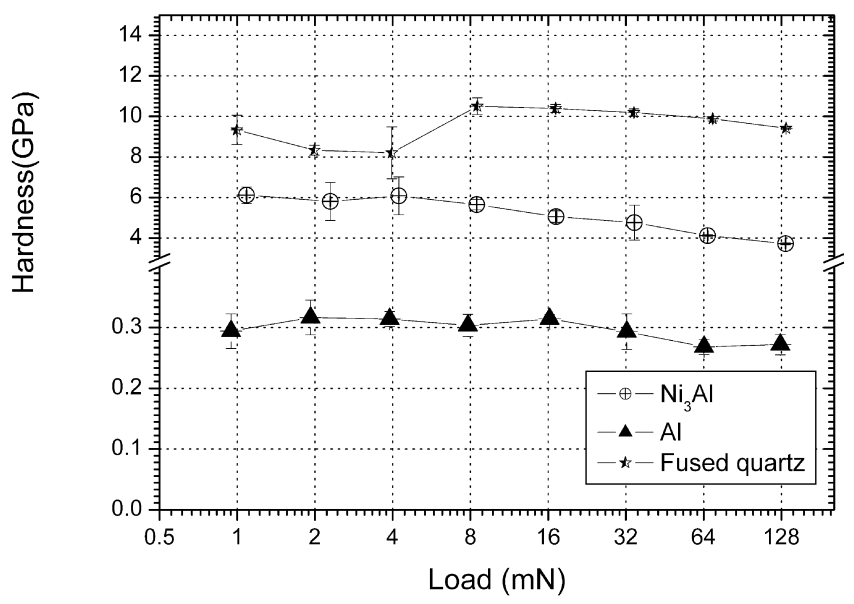

FIG. 13. Variation of hardness with peak load for the three materials.

The results in Fig. 12 also indicate that in fused quartz, the stress exponent also exhibits a strong dependence on indent size. In the bulk deformation of glasses, however, it is well known that the stress exponent, defined as $n=\partial \dot{\epsilon} / \partial \sigma$, is a strong function of stress even at constant temperature. ${ }^{33}$ The room-temperature nanoindentation situation here should correspond to the low-temperature, high-stress regime of the deformation of bulk glasses in which the deformation mode is thought to be due to the intense shearing of localized disk-shaped volumes. ${ }^{33}$ The analysis by $\operatorname{Argon}^{33}$ in fact predicts that at low temperatures, the stress exponent is given by

$$
n=f\left(\tau / \tau_{\mathrm{o}}\right) \frac{\tau_{\mathrm{o}} \Omega_{f}}{\mathrm{k} T},
$$

where $\Omega_{\mathrm{f}}$ is the shear volume, $\tau$ is the applied shear stress, and $\tau_{\mathrm{o}}$ is the ideal shear strength. The function $f$ is symmetrical about $\tau / \tau_{\mathrm{o}}=0.5$ and decreases toward zero as $\tau / \tau_{\mathrm{o}}$ increases or decreases from 0.5 . For large stresses $\left(\tau>0.5 \tau_{\mathrm{o}}\right)$, the stress exponent should therefore increase as the stress decreases. However, the current results in Fig. 13 indicate that the hardness of fused quartz does not exhibit a significant size effect, and so the varying stress exponent cannot be explained by a changing stress as the indent size increases. If Eq. (8) is valid for the nanoindentation situation, then the only conclusion is that the shear volume $\Omega_{\mathrm{f}}$ decreases as the indent size decreases. As the indent size increases, the shear volume should increase, but not indefinitely; in fact, it should saturate to the bulk deformation value as the indent size enters the microdeformation regime. The fused quartz results in Fig. 12 in fact indicate that as the indent depth exceeds approximately $300 \mathrm{~nm}$, the stress exponent saturates to a 
value between 60 and 80 . The observed variation of the stress exponent from approximately 1 to about 80 in Fig. 12, according to Eq. (8), should in fact reflect a variation of $\Omega_{\mathrm{f}}$ by approximately 80 times, as the indent increases from a few tens of nanometers to over $1 \mu \mathrm{m}$ in depth. Physically, the shear volume $\Omega_{\mathrm{f}}$ may correspond to atomic-sized shear transformation zones ${ }^{33}$ for the smallest indents to submicrometer-sized shear cracks for the micrometer-sized indents. It should be noted that Eq. (8) was derived by approximating the shearing of the volume $\Omega_{\mathrm{f}}$ by the generation of a dislocation loop of the same size, ${ }^{33}$ and hence should be applicable to both the situation of an atomic-sized shear zone and a submicrometer crack. The current explanation involving the transition of the critical shear volume from an atomic size cluster to a submicrometer crack is nevertheless quite conjectural, and more investigations, both experimental and theoretical, should be performed to gain deeper understanding into the problem.

\section{CONCLUSIONS}

(1) The stress exponents of the constant-load indentation creep in three materials, namely, $\mathrm{Ni}_{3} \mathrm{Al}, \mathrm{Al}$, and fused quartz, are found to be small at small loads. In $\mathrm{Al}$ and fused quartz, the stress exponents measured for the smallest indents approach unity. The stress exponents in all the three materials increase very rapidly as the indent size increases, exhibiting an intense size effect.

(2) The size effect of the stress exponent in the two metals $\mathrm{Ni}_{3} \mathrm{Al}$ and $\mathrm{Al}$ signifies that the mechanism for the indentation creep changes as the indent size increases. The mechanism may transit through linear diffusional flow (for $\mathrm{Al}$ at least) to climb-controlled to eventually glide-controlled processes as the indent size increases toward the microdeformation regime. For the amorphous fused quartz, the size effect on the stress exponent can be explained by a reduction of the localized shear volume as the indent size decreases.

(3) The creep of submicrometer-sized indents in different materials and experimental conditions remains a largely unknown area to explore. The state of the matter under the indenter is probably unique in terms of the large magnitude of the compressive stress, the proximity to free surfaces, and the high density of dislocation debris in crystalline specimens. Deviations from bulk behavior are certainly expected, and more experimentation and theoretical modeling are required to gain a deeper understanding of this important phenomenon in both crystalline and amorphous materials.

\section{ACKNOWLEDGMENTS}

The work described in this paper was supported by a grant from the Research Grants Council of the
Hong Kong Special Administration Region, People's Republic of China (Project No. HKU7083/02E). We also thank G. Feng for allowing us to use Fig. 2 from his thesis.

\section{REFERENCES}

1. C.F. Robertson and M.C. Fivel, J. Mater. Res. 14, 2251 (1999)

2. Y.L. Chiu and A.H.W. Ngan, Acta Mater. 50, 2677 (2002).

3. M.J. Mayo and W.D. Nix, Acta Metall. 36, 2183 (1988).

4. W.R. LaFontaine, B. Yost, R.D. Black, and C.Y. Li, J. Mater. Res. 5, 2100 (1990).

5. S.P. Baker, T.W. Barbee, Jr., and W.D. Nix, in Thin Films: Stresses and Mechanical Properties III, edited by W.D. Nix, J.C. Bravman, E. Arzt, and L.B. Freund (Mater. Res. Soc. Symp. Proc. 239, Pittsburgh, PA, 1992), p. 319.

6. B.N. Lucas and W.C. Oliver, in Thin Films: Stresses and Mechanical Properties III, edited by W.D. Nix, J.C. Bravman, E. Arzt, and L.B. Freund (Mater. Res. Soc. Symp. Proc. 239, Pittsburgh, PA, 1992), p. 337.

7. K.M. O'Connor and P.A. Cleveland, in Thin Films: Stresses and Mechanical Properties IV, edited by P.H. Townsend, T.P. Weihs, J. Sanchez Jr., and P. Borgesen (Mater. Res. Soc. Symp. Proc. 308, Pittsburgh, PA, 1993), p. 495.

8. V. Raman and R. Berriche, J. Mater. Res. 7, 627 (1992).

9. B.N. Lucas and W.C. Oliver, Metall. Mater. Trans. 30A, 601 (1999).

10. G. Feng and A.H.W. Ngan, Scr. Mater. 45, 971 (2001).

11. G. Feng and A.H.W. Ngan, J. Mater. Res. 17, 660 (2002).

12. A.H.W. Ngan and B. Tang, J. Mater. Res. 17, 2604 (2002).

13. B. Tang and A.H.W. Ngan, J. Mater. Res. 18, 1141 (2003).

14. S.A. Syed and J.B. Pethica, Philos. Mag. A 76, 1105 (1997).

15. W.B. Li, H.L. Henshall, R.M. Hooper, and K.E. Easterling, Acta Metall. Mater. 39, 3099 (1991).

16. W.C. Oliver and G.M. Pharr, J. Mater. Res. 7, 1564 (1992).

17. P.M. Sargent, Use of the Indentation Size Effect on Microhardness for Materials Characterization, edited by P.J. Blau and B.R. Lawn (American Society for Testing and Materials, Philadelphia, PA, STP 889, pp. 225-241.

18. W.D. Nix and H. Gao, Journal of the Mechanics and Physics of Solids 46, 411 (1998)

19. YA.M. Soifer and A.V.A.L.R., Mater. Lett. 56, 127 (2002).

20. A.A. Elmustafa and D.S. Stone, Acta Mater. 50, 3641 (2002).

21. J.P. Poirier, Creep of Crystals-High Temperature Deformation Processes in Metals, Ceramics and Minerals (Cambridge University Press, Cambridge, U.K., 1985).

22. A.F. Bower, N.A. Fleck, A. Needleman, and N. Ogbonna, Proc. R. Soc. London, Ser. A 441, 97 (1993).

23. M. Sakai, Philos. Mag. A 82, 1841 (2002).

24. M. Sakai and S. Shimizu, J. Am. Ceram. Soc. 85, 1210 (2002).

25. T.P. Weihs and J.B. Pethica, in Thin Films: Stresses and Mechanical Properties III, edited by W.D. Nix, J.C. Bravman, E. Arzt, and L.B. Freund (Mater. Res. Soc. Symp. Proc. 239, Pittsburgh, PA, 1992), p. 319.

26. I.N. Sneddon, Int. J. Eng. Sci. 3, 47 (1965).

27. Y.L. Chiu and A.H.W. Ngan, Acta Mater. 50, 1599 (2002).

28. G. Feng, M.Phil. Thesis, University of Hong Kong, Hong Kong, Japan, (2001).

29. W.B. Li and R. Warren, Acta Metall. Mater. 41, 3065 (1993).

30. J.R. Spingarn, D.M. Barnett, and W.D. Nix, Acta Metall. 27, 1549 (1979).

31. R.W. Ballufi, Phys. Status Solidi 42, 11 (1970).

32. P.B. Hirsch, Prog. Mater. Sci. 36, 63 (1992).

33. A.S. Argon, Acta Metall. 27, 47 (1979). 